\title{
Adoption of New Information Economics for Informational System Development in Modern Day Call Center
}

\author{
Settapong Malisuwan, Navneet Madan, Wassana Kaewphanuekrungsi, and Napaporn Petchinda
}

\begin{abstract}
Business organizations should adopt New Information Economics Model together with System Development Life Cycle as a guideline to improve and manage information systems. Modern day call centers are increasingly complex, and have to ensure they are specialized in variety of areas of the business in order to resolve modern day knowledgeable customer complaints. Therefore, few organizations today have successfully managed Call Center to ensure customer satisfaction is reached. The aim of this research is to recommend Call Centers to adopt New Information Economics Model (NIE) to facilitate their organization's Call Center departments. This research adopts Qualitative method using interviews and surveys to solicit expert opinion in a company in Thailand. The analysis in this research identifies key issues in Call Center implementation with regards to planning stage and adequate employee training which has a significant relationship to rapidly technological changes that influences Call Center information system. This research aims to provide recommendations in future development of Call Center management models for business organization and proposes a framework for future study for Call Center management especially in planning up to implementation stage.
\end{abstract}

Index Terms - Call center implementation, New Information Economics (NIE), System Development Life Cycle (SDLC), and Thailand.

\section{INTRODUCTION}

The concept of international trade is not new but the introduction of internet and digitalization has intensified e-commerce leading us into globalization era which brings about a plethora of business opportunities and challenges. Centralized call center service industry is an exemplar of globalization of services, so the motivation to establish these centers arises from the increase in importance of customer services; availability of low-cost telecommunications afforded by internet; and decreased costs from economies of scale. Effectual and efficient management of call center operations is one essential key strategy to achieve business performance excellence particularly for multinational organizations. As call center operations is the front-office of the organization where interaction between the organization and customers takes place, failure to successfully implement such operations can deter an organization's performance substantially. Centralized call centers that arise from

Manuscript received August 20, 2013; revised October 24, 2013.

Navneet Madan is with the National Broadcasting and Telecommunications Commission, Thailand (e-mail: navneet.nbtc@gmail.com). ecommerce and globalization are complex in nature as it involves understanding diverse consumers from worldwide therefore creating the need for both global and local customer solutions. At present, call centers are becoming more multidisciplinary in nature. As opposed to just servicing customers, they are required to provide multiple functionalities thus requiring a more complex information system design. Accordingly, this calls for complex information systems that support dual service and sales roles which results in good customer response times, higher service quality, increased customer satisfaction and elevated incremental revenues from higher sales. Consequentially, the most powerful manifestation of centralized and multidisciplinary call centers is the challenge to coordinate multiple functionalities of these call center activities by means of information system. Besides improving the effectiveness of software development is one of the top priorities for information system design and management [1]. To emphasize, it is vital for information system platform and software development to embody multiple functionalities that are critical to the successful implementation of call center operations. Information system design failures primarily occur from vague project goals, project scope thus leading to ambiguous project planning. Although information systems are developed to accomplish business goals successfully, misinterpretation by information technology management or ambiguous call center project goals set by business management can lead to failure in information system design. System Development Life Cycle (SDLC) is a conceptual model adopted by organizations to guide its information system design from initial planning stages through to implementation and then to maintenance. However, SDLC is a generalized model that guides the processes required for information system design, whereas, New Information Economics (NIE) is a tool that ensures clarity in project goals and scope between business management and information management. As mentioned earlier, incoherence between business goals and information system designed to support business goals have lead to many project failures. Therefore, the primary purpose of this study is to provide call centers with an effectual and effective information system design by encouraging the adoption of NIE mutually with SDLC.

\section{Call Center System}

Traditional call centers were defined as "any group whose principle business is talking on the telephone to customer or 
prospects". The concept of call centers was introduced in 1980s for the purpose that customer relationship between organization and users do not end right after sales transaction has ended. A decade ago it was realized that organizations needed interaction with their customers beyond store doors. For this reason, the concept of call centers was created to be the front-office for organizations to create, maintain and manage customer relationships by resolving complaints, answering customer inquiries with some even available for 24 hours and 7 days a week. The channel for interaction between organization and users has been extended from just telephones to include channels such as email, fax, short message service (SMS), chat, and web forms. Along with the added complexity of multiple communication channel availability, modern day educated and demanding consumers also calls for higher service requirements resulting in new challenges in modeling, analysis and design of call centers [2]. These extended ranges of services and channels for customer and organization interaction have increased complexity for call center management. Therefore, at present call centers can be defined as a group or department in an organization that interacts with customers or prospective customers through any one or multiple communication channels.

Call center is confronted with many challenges, including wide range and complex customer enquiries. Modern day customers expect on the spot answers to their inquiries thus employees are required to be knowledgeable in wide variety of areas therefore training new staff is very important. Moreover due to high level of stress in serving customers there is high staff turnover. Call center implementation also requires "continuous tracking and assessment of efficiency measures" This can be resolved through New Information Economics Model (NIE).

In ensuring the modern call center is implemented successfully, knowledge management is required to resolve issues such as reducing customer representative training time and costs, improve call response and handling time, increase customer satisfaction, employees are more able to provide accurate information to customers, more flexibility in handling customer call center processes, able to cooperate with other business departments, and lastly ensure fewer calls are transferred to help desks [3]:

In addition to answering phone calls, many call centers now respond to customers via online chats and email queries. Organizations have broadened responsibility of call center representations and thus their additional workload should be managed with improved call center process implementation [4].

"The call center knowledge repository can be used in a number of practical ways" [4]:

- "Publish a selection of customer questions (FAQs) to website.

- Ensure online sales and product information is accurate and comprehensive. This will reduce the number of calls in these areas.

- Develop 'standard response' to a range of common e-mail exist that will analysis incoming e-mail, and automatically select appropriate responses" [4].

It is important that the information provided to customers is drawn out of the same repository used by call center staff. In this way, duplication is reduced, error is avoided thereby redundant maintenance efforts will also be reduced. Fig. 1 illustrates the call center process implementation of the company used as a case study in this research.

The multi-communication channels available for interaction between organization and consumer results in operational complexity. Customer inquiries and complaints within this organization have to pass through three subsequent stages which are prepare, review and release. In the "preparation" stage, appropriate grouping of information and the structure is determined. In the review stage, quality of the information is analyzed and quality assurance is conducted. In the release stage, Frequently Asked Questions (FAQ) that is product information and typical inquiries often asked by consumers are published on the organization website. For instance, FAQ could be extended to generate standard responses, a system that analyzes incoming emails and automatically replies with relevant answers. To sum up, the implementation of call center activities which require the collection of customer inquiries from multiple communication channels and then ensuring these information passes through three subsequent stages results in operational complexity which calls for a multi-functional information systems platform.

As such, a corporate could diminish its training time and costs for new staff. Allow organization to store, disseminate, re-use corporate information and experience, with the goal of synthesizing knowledge to improve business operations[5].

\section{NEW INFORMATION ECONOMICS}

The New Information Economics (NIE) is a tool to ensure the coherence between business and information system goals in order to design and implement a successful information system platform that fulfills business goals. Benson et al. 2004 has developed five basic management practices used in the Strategy-to-Bottom-Line Value Chain in order to control the IT budget. Fig. 2 shows Strategy-to-Bottom-Line Value Chain. The planning model provides a specific guideline for business manages in adapting the process from planning till achieving successful implementation [3], [6].

The set of five management practices, called New Information Economics (NIE), is comprised of (1) Supply/Demand Planning, (2) Innovation, (3) Prioritization, (4) Alignment, and (5) Performance Measurement. NIE is set of criterion that integrates business and IT management goals, and guides management on which new project will fit the overall information system direction in achieving organization goals [3].

- NIE practice 1: Strategic demand/supply planning

The first stage involves determining the company's strategic intentions. Companies will convert their goals into implementable IS. It is required that business and IS cooperate in this stage to determine the demand (what is the goal) and what is required (what can IS supply to support business goals) [6]. In Fig. 2, strategic planning includes business strategic intentions, a strategic IS agenda and IS requirements [3]. 
- $\quad$ NIE practice 2: Innovation

Innovation is novel idea that translates into new products and services, which enhances the competitiveness of an organization. Innovation in IS capabilities will create new business opportunities for an organization and increase efficiency in supporting business activities through IS. Although businesses rarely change their strategies based on technological innovations, but if innovation matches the business strategic intentions then a sound strategic IS agenda can be pursued [3].

\section{- NIE practice 3: Prioritization}

Companies should invest only on IS projects that directly support the goals of the business which is in this case the call center. This practice pushes managers to prioritize or select IS projects that will help improve the call center by ensuring processes are easily followed so customer representative employees can serve the customers efficiently. "IS projects should be based upon potential future business impacts and then assign resources to the highest valued IS projects for the call center" [6].

"Prioritization should be implemented in strategic intentions, a strategic IS agenda, strategic IS requirement, project planning, and project budgeting, to propose the project with the highest rate of returns"[6] (see Fig. 2).

\section{- NIE practice 4: Alignment}

This stage requires the cooperation of business and an IT manager in identifying which existing IS projects directly improves the Call Center implementation process in order to identify projects that should be eliminated. "This practice aligns an assessment of activities in portfolios with the strategic IS plan, the strategic IS requirements, and light-on budgets parts, and it identifies resources for these activities"[6]. Alignment stage is the same as prioritization stage, however, alignment requires determining the required processes existing IS application projects. Before starting the implementation stage of a project, alignment of IS projects must be checked. "If there is poor alignment it is likely the new information system will encounter difficulties and delays" [4].

- NIE practice 5: Performance measurement

This involves evaluation of both IS performance and how it impacts business in a way that relates to business goals. "It is easy to measure IS performance in a tactical way but difficult to measure IS impact on business"[6]. Additionally, IS managers should communicate business performance that are resulting from IS implementation to business managers in order to increase their comprehension on the impact of IS in making call center business process easier and more effective. It is a known fact that investment in IS projects that directly improve business, will produce great value and have a great impact on a company's performance.

The purpose of this study is to identify significant problems to the Call Center implementation process and solutions from a managerial perspective [4].

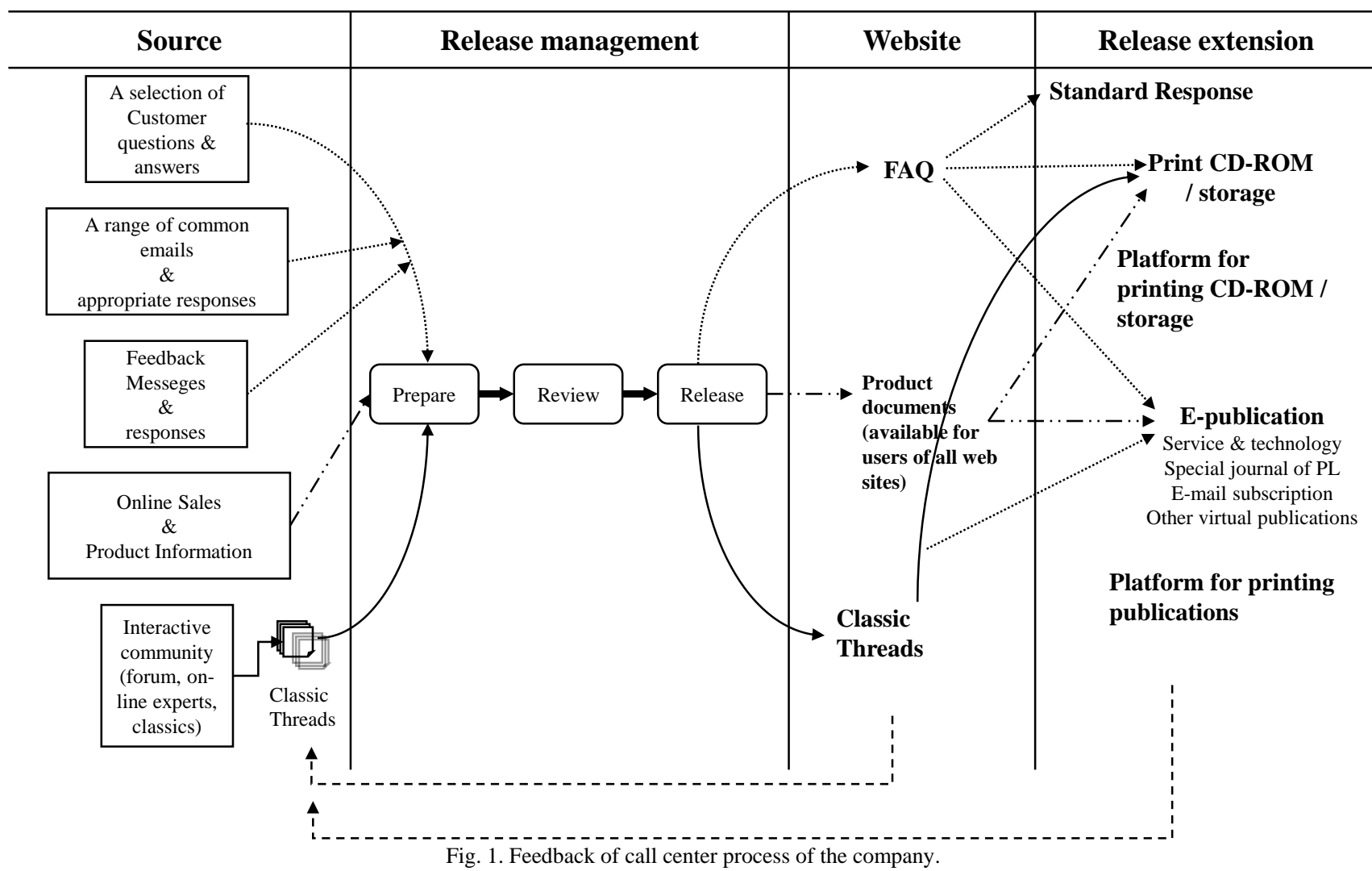

\section{System DeVElopment LIFE CyCLE (SDLC)}

Information system developers use a sequential formal system development model called System Development Life Cycle (SDLC). Traditional System Development models have five sequential steps that go about into originating information systems solutions to fulfill organizational problems or organizational goals [7]. SDLC can be defined as a model for developing an information system as a problem-solving process with sequential steps and options for revisiting steps when problems appear [8]. SDLC embodies a set of general categories that show major and 
significant sequential steps required to developing an information system for an organization. First, system analysis is a stage where problem, causes, alternate solutions and information requirement is clarified. However, feasibility of the solution is also analyzed in this phase organizational, technological, legal and economic factors are identified. In this stage, constraints are also defined. Second stage involves system design where it must be demonstrated how information system is a solution to the organization problem or how it can fulfill a business opportunity. This step is the planning stage of the Information system development process [9]. Coding is the third phase of the SDLC model. Programming or coding involves the translation of information design specifications into the program code. This step is the responsibility of information system specialists who write software or have expertise in selection and purchase of software package from external software providers. The fourth stage involves testing, which is a thorough process of identifying an errors and imperfections that the software may have in impeding it from producing desirable results under known conditions [8]. The testing phase must be conducted thorough before full implementation of the system. The fifth stage, the implementation stage requires conversion from old to new system. This involves stages such as parallel strategy, direct cutting over, pilot study and phase approach [8]. Operation and maintenance stage is the final phase which helps determine how well the system meets the required standards and how well it solves the organization problem at hand. A system must be consistent in maintaining good performance and able to correct errors when necessary. Especially in call center management project, a organization is required to have many types of activities in a centralized system in order to efficiently cater to requirements of the consumers. Therefore, managing multifunctional software is one of the biggest challenges for system development. The SDLC takes into account an IS perspective whereas, NIE is a tool takes into account the business perspective and ensure coherence between business goals and Information system development implementation. New Information Economics practices play a key role in helping business managers' process system development.

\begin{tabular}{|c|c|c|c|c|c|c|}
\hline \multirow{5}{*}{$\begin{array}{l}\text { Business } \\
\text { Strategic } \\
\text { Intentions } \\
\text { (1) (2) (3) }\end{array}$} & Strat & ic IS Planning & & Annual IS & lanning & \\
\hline & \multicolumn{5}{|c|}{ The Business Enterprise: Lines of Business, Departments } & \\
\hline & \multirow{4}{*}{$\begin{array}{l}\text { Strategic IS } \\
\text { Agenda } \\
\text { (1) (2) }\end{array}$} & \multirow{4}{*}{$\begin{array}{l}\text { (1) (3) (4) } \\
\text { Strategic IS } \\
\text { Requirement }\end{array}$} & \multicolumn{2}{|c|}{ Business Plan (Annual) } & \multirow{3}{*}{$\begin{array}{c}\text { Projects Budget } \\
\text { (3) }\end{array}$} & \\
\hline & & & \multirow{3}{*}{$\begin{array}{l}\text { (3) (5) } \\
\text { Projects }\end{array}$} & (3) & & 5) \\
\hline & & & & Project Plan & & Actio \\
\hline \multirow{4}{*}{$\begin{array}{l}\text { Assessed } \\
\text { Portfolios } \\
\text { (4) (5) }\end{array}$} & & & & (Annual) & Lights-on & \\
\hline & $\begin{array}{l}\text { Plan } \\
\text { (4) (5) }\end{array}$ & & \multicolumn{2}{|c|}{ IS Plan (Annual) } & & \\
\hline & \multicolumn{5}{|c|}{ The IS Enterprise: Four "Lights-on" Asset Pools } & \\
\hline & \multicolumn{5}{|c|}{ Performance Measurement Metrics } & \\
\hline
\end{tabular}

\section{ReSEARCh Methodology}

The research adopts qualitative method using descriptive interviews and surveys to seek expert opinion [10]. This survey seeks to identify the most problematic issues in call center implementation in an organization in order to originate an information system to resolve common issues. From the results of the research, descriptions and definitions of common issues in call center implementation process was described to assist in resolving issues for the call center department. The study was conducted in two stages and involves an analysis and review of the common issues that call center representatives face on a day to day basis in their organization. The first stage involves designing an issue database. The categorization of the issues is based on a system created from the interview conducted in this study. These categories were determined by scrutinizing the office environment and by interviewing management-level staff. The second stage of the study involves pilot testing and improving the survey instrument. The instrument is designed to provide a descriptive view of the perceptions of the customer representatives within the organization in regards to Call Center process implementation.
Each respondent was asked to rank problematic issues with regard to his or her organization in the Call Center implementation processes. The organization selected for this case study is an organization that imports and sells industrial products, advantage technological products and is also an internet provider in Thailand. 245 of 700 employees were selected as a sample which is $35 \%$ of total employees within the company.

\section{RESULTS AND ANALYSIS}

The results of the study are shown in Table I, Table II, and Table III. As anticipated within the literature by many researchers, different views and misunderstanding between business managers and IT managers is the main cause of IS project failure [6]. In other words, business and IT disconnection can cause failure in call center information system implementation. Cooperation among business managers and IT managers is crucial especially in the planning stage. $40 \%$ of the staff rated that individual support as a crucial aspect in planning stage of Call Center project. And extremely problematic (see Table I). This can cause a disconnection between business and IT managers. Moreover, 
$50.5 \%$ of agree that budget is also crucial and $38 \%$ agree that these issues are because of incompetent strategic planning. The IT managers control the Call Center system development process while the business manager runs the business in respect to pursuing organization strategy and goals. This proves that difference in IS and business perspective cannot be resolved by sole adoption of SDLC but requires NIE implementation as well.

Both must be able to develop a new project within limited budget. Applying NIE jointly with SDLC to ensure coherence and eliminate IT-business disconnection is the contribution of this research.

TABLE I: PRoBlematic ISSUES FOR CALl CENTER PlanNing

\begin{tabular}{|l|c|c|c|c|}
\hline \multirow{2}{*}{\multicolumn{1}{|c}{ Issue }} & \multicolumn{3}{c}{ Problematic (\%) } & \multirow{2}{*}{$\begin{array}{c}\text { Missing } \\
(\%)\end{array}$} \\
\cline { 2 - 5 } & $\begin{array}{c}\text { Not at } \\
\text { all }\end{array}$ & Somewhat & Extremely & \\
\hline $\begin{array}{l}\text { Lack of a Strategic } \\
\text { Plan }\end{array}$ & 15.5 & $\mathbf{5 4 . 5}$ & 21.0 & 9.0 \\
\hline Organizational Directive & 16.5 & 47.0 & 23.5 & 13.0 \\
\hline Organizational Expertise & 20.5 & 47.5 & 17.0 & 15.0 \\
\hline Individual Expertise & 9.5 & 55.5 & 28.5 & 6.5 \\
\hline Existing System & 13.0 & $\mathbf{5 6 . 5}$ & 23.0 & 7.5 \\
\hline $\begin{array}{l}\text { Lack of a Planning } \\
\text { Model }\end{array}$ & 21.0 & 44.5 & 26.0 & 8.5 \\
\hline Internal Leadership & 20.5 & 40.0 & 25.5 & 14.0 \\
\hline Organizational Culture & 20.5 & 45.0 & 20.5 & 14.0 \\
\hline Organizational Support & 21.0 & 43.0 & 28.0 & 8.0 \\
\hline Budgeting Issues & 18.5 & 34.0 & $\mathbf{3 8 . 0}$ & 9.5 \\
\hline $\begin{array}{l}\text { Rapidly Changing } \\
\text { Technology }\end{array}$ & 22.5 & 35.5 & 35.5 & 6.5 \\
\hline Individual Support & 18.5 & 31.0 & $\mathbf{4 4 . 0}$ & 6.5 \\
\hline Personal Issues & 19.0 & 32.5 & 41.5 & 7.0 \\
\hline Other & 15.0 & 14.0 & 3.0 & 68.0 \\
\hline
\end{tabular}

TABLE II: PROBLEMATIC ISSUES FOR CALL CENTER PROCUREMENT

\begin{tabular}{|l|c|c|c|c|}
\hline \multirow{2}{*}{\multicolumn{1}{|c|}{ Issue }} & \multicolumn{3}{c|}{ Problematic (\%) } & \multirow{2}{*}{$\begin{array}{c}\text { Missing } \\
(\%)\end{array}$} \\
\cline { 2 - 5 } & $\begin{array}{c}\text { Not at } \\
\text { all }\end{array}$ & Somewhat & Extremely & \\
\hline $\begin{array}{l}\text { Lack of a Strategic } \\
\text { Plan }\end{array}$ & 19.15 & $\mathbf{4 6 . 0}$ & 29.5 & 5.0 \\
\hline Budgeting Issues & 10.0 & 34.5 & $\mathbf{5 0 . 5}$ & 5.0 \\
\hline Individual Support & 29.0 & 37.5 & 28.0 & 5.5 \\
\hline Organization Culture & 17.5 & 51.0 & 26.5 & 5.0 \\
\hline Organization support & 37.0 & 39.5 & 18.5 & 5.0 \\
\hline Other & 30.5 & 11.0 & 5.0 & 53.5 \\
\hline
\end{tabular}

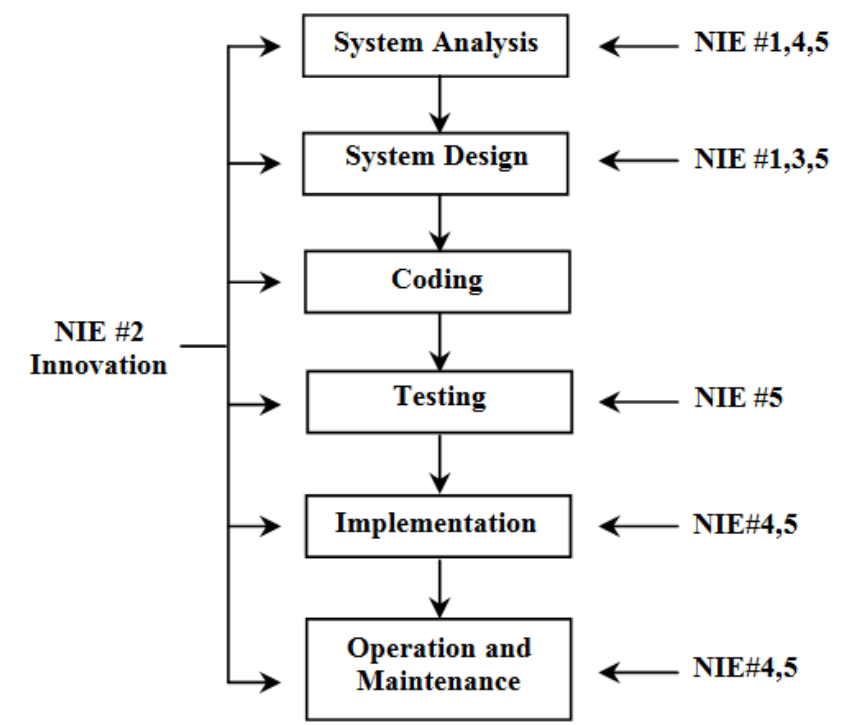

Fig. 3. System Development Life Cycle and New Information Economics (NIE-SDLC) framework.
Fig. 3 shows NIE-SDLC framework. NIE five practices are brought to improve the system development and connect Call Center and management goals.

This shows the company doesn't have good planning. Lack of planning can result in incorrect budgetary direction and increasing spending on managerial time on unnecessary activities. The company should ensure that planning stage is implemented effectively and thus time and investment should be focused on Call Center activities that directly impact the business bottom line.

The planning stage will guide managers from translating business strategy into actionable activities.

The results of this research lead to propose new model (Fig. 3) as mention below.

\section{A. System Analysis}

The system analysis of this company shows that this company does not have good planning, procurement and implementation of the plan. The results indicate that it received $54.5 \%, 46 \%$ and $70.5 \%$ as somewhat problematic in strategic plan for planning, procurement and implementation. Top managers conduct planning by defining what the strategic business intentions of a business is serving future Call Center requirements. If planning is implemented well the company should know the requirements of a modern day call center (demand) and what IS must do to service them and improve the call center's business process (supply). NIE Stage 1 in strategic demand and supply planning will help scrutinize the what is wrong with the current business model and what types of activities or process should be discarded or modified [7].

A key requirement during the analysis phase is to review the business goal and action plans required to achieve that business goal [2]. In knowing clearly the demand, IT managers are more capable in determining the appropriate project and what is required of the department "Call Center" which is supply. Moreover, the business manager must help the IS project team understand the user requirements and how users must be training to understand the IS system. However, it must be noted that User's lack of experience makes it increasingly difficult in determining system requirements [11].

Therefore, business managers to speak to customer representatives who are experienced users of the system or the Call Center business in the firm to determine what is required to be achieved by the business process to support the user. This is why NIE\#1 strategic demand/supply planning is crucial for system analysis.

Strategic planning includes implementation planning for users that employees will not resist new technology. The second issue in is training of Call Center representatives as shown in Table III. Business managers should ensure employee training is in the plan to ensure employees are properly trained for the job. The results indicate that there is issues in planning stage in the existing system process with $56.5 \%$ agreeing it is somewhat problematic. Moreover, it is indicated that the existing system implementation is also problematic with $38 \%$ of users agreeing it is problematic. Therefore, the alignment stage from NIE should be able to help determine what existing activities or IS projects should be removed and not implemented. Therefore, business managers need not overspend on unnecessary IS activities 
that no longer provide a valuable impact on the Call Center department.

TABLE III: PROBLEMATIC ISSUES FOR CALL CENTER IMPLEMENTATION

\begin{tabular}{|c|c|c|c|c|}
\hline \multirow{2}{*}{ Issue } & \multicolumn{3}{|c|}{ Problematic (\%) } & \multirow{2}{*}{ Missing (\%) } \\
\hline & Not at all & Somewhat & Extremely & \\
\hline Lack of a Strategic Plan & 14.5 & 70.5 & 12.5 & 3.0 \\
\hline Organizational Directive & 12.5 & 54.0 & 28.5 & 5.0 \\
\hline Organizational Expertise & 18.5 & 58.5 & 18.0 & 5.0 \\
\hline Individual Expertise & 16.0 & 44.0 & 37.0 & 3.0 \\
\hline Existing System & 22.5 & 37.5 & 38.0 & 2.0 \\
\hline Internal Leadership & 19.0 & 46.0 & 33.0 & 2.0 \\
\hline Training & 13.5 & 40.5 & 45.5 & 1.5 \\
\hline External Consultants & 31.0 & 40.0 & 27.5 & 1.5 \\
\hline Organizational Culture & 24.0 & 54.5 & 20.0 & 1.5 \\
\hline Organizational Support & 37.5 & 38.0 & 22.5 & 2.0 \\
\hline Budgeting Issues & 19.0 & 56.5 & 22.5 & 2.0 \\
\hline Rapidly changing Technology & 11.5 & 55.0 & 32.0 & 1.5 \\
\hline Personal Issues & 21.5 & 53.0 & 24.0 & 1.5 \\
\hline Other & 24.0 & 18.0 & 8.5 & 49.5 \\
\hline
\end{tabular}

Performance measurement (NIE\#5) requires software testing [12]. This research shows that performance testing should start early on during the system development process. This allows for system errors to be seen during the testing phase and can mitigate risks of IS being ineffective once it's completed.

\section{B. System Design}

Project team has to determine the call center solutions and a set of alternative solutions that matches business goals. Prioritization in NIE Stage 3 helps determine the most valued IS project that will be a solution for the call center process implementation on a day to day basis. Prioritization and alignment if implemented correctly will help in determining which projects or activities are critical therefore, it is crucial in determining budgetary direction. NIE 1 is the most important stage in what is required in designing a brand new system for the Call Center. After IS team designs the new system, Performance Measurement NIE Stage 5, is the most critical stage to analyze the impact of the IS system in achieving business goals of the Call Center.

\section{Coding}

Top managers would let software experts for programming. New software languages, which make programmers work easier, are the ways helping them. Coding using new software is an Innovation (NIE\#2) but this requires IS experts. However, existing coding languages can be adopted to create an entirely new IS system which also contributes as an innovation within that organization. Moreover, the innovation using coding language to create a system that is specific to an organization is a type of innovation which is not transferable from one organization to another. This is because each organization has different needs therefore may require a IS system that is specific to their own organization.

\section{System Testing}

Performance and Measurement (NIE\#5) is used in testing phase. This phase will help define whether the system works and meets the business goals that were enacted in the planning stage [9]. In this stage, IT managers are not only required to test the new system but business managers must also identify whether the system helps improve and achieve business goals. This stage is critical as top managers must rely on performance measurement and evaluation to come to a conclusion on whether the Call Center performance is improved as a result of the Information System and whether it helps the Call Center department meets its business goals. The bottom line impact of the business should be measured.

\section{E. Implementation of the IS System}

As aforementioned, since that the problem arises from the lack of a good planning model, it has lead to an issue in achieving success in call center business process on a daily basis. This research determines that if the analysis and designing was appropriately done during the planning stage, this should lead to success in implementation. Moreover, as identified in this research, it is also crucial for employees to be trained, in order to increase user experience in making effective use of the IS system. Implementation in the NIE Stage 5, involves conversion changing the old system to the new or making modifications to old system and resulting in a new and more efficient system. There are four types of conversions, IT managers must make a choice as which conversion is most appropriate for this Call Center process. It is also crucial that top managers actively participate in implementation phase as it is the most crucial phase in achieving Information System success. This is because to judge whether the IS project for the Call Center is a success, the business managers will consider the outcome during the implementation stage. Hence, they should be actively involved during the implementation stage.

\section{F. Maintenance and System Update}

The alignment (NIE 4) is critical for operation and maintenance for the Call Center implementation project, in order to determine what existing IS should be updated and what should be eliminated. In this stage, the team must measure the current performance of the system to determine what kind of updating is required. If the system is required to be updated, it must match the new business goals and the strategic intentions of the top business managers.

Performance measurement (NIE\#5) is generated. 
Successful Information system design comes from a good plan in designing that Information System. If a company does not clearly indicate the demand, then IS team cannot determine what is required (supply) to accomplish that demand.

There is no universal solution in designing a Call Center infrastructure because each firm must design its own Call Center to accomplish the specific requirements of its business [10]. Innovation (NIE\#2) can occur in any phase. An innovative environment will increase efficiency and effectiveness in Call Center implementation process and helps in following trends in satisfying ever changing demand of consumers. The results indicate that $32 \%$ of users indicate that there it is problematic in terms of "Rapidly Changing Technology" in implementation of Call Center process. Therefore, in this organization, IS team should leave room in updating the software to ensure there is freedom to keep updating the IS system in order to follow rapidly changing trends. However, it must also be realized that not all technological trends will match your business process hence; it must be analyzed on whether these new technologies comply with what your organization demands.

\section{CONCLUSION}

The primary objective of this study is to identify significant problems in implementation of information system in call center as a case study. Therefore, the concept of NIE is introduced. This study proves that SDLC for information system development solely cannot eliminate business and IT disconnection in information system design development. This particular company has failed in since the planning stage, and lack of a rational planning can lead of organizational direction which can result in excessive budget, more IT spending and unnecessary management time on unimportant activities. NIE as a strategic model for information system design and development can help managers translate business strategy into practical information system implemented in call center, thereby resulting in successful information system built for call center implementation. To emphasize, it is vital for information system platform and software development to embody multiple functionalities that are critical to the successful implementation of call center operations. Information system design failures primarily occur from vague project goals especially in this case where, SDLC was implemented unaccompanied by NIE as a business tool. NIE can ensure that innovation is in every step of system development while also ensuring that unnecessary innovation project is not pursued. Performance and Measurement from NIE model plays role in all SDLC phases, except Coding. Strategic demand/supply planning and Alignment of NIE is implemented in system analysis stage of SDLC. Strategic demand/supply planning and Prioritization of NIE is implemented in system design of SDLC. Alignment stage in NIE is in implementation and operation and maintenance of SDLC. In conclusion, business managers must apprehend that NIE is critical in information system design of modern day multifunctional call centers. As a result, NIE as a strategic tool that when adopted jointly with SDLC will ensure successful bottom line for the organization.

\section{ACKNOWLEDGMENT}

The authors wish to acknowledge with gratitude and appreciation, Assumption University for the opportunity they have given the author to complete this research for her $\mathrm{PhD}$. The authors would also like to express sincere gratitude to reviewers of this journal for their valuable input.

\section{REFERENCES}

[1] M. Akmanligil and P. C. Palvia, "Strategies for global information systems development," Information \& Management, vol. 42, 2004, pp. 45-59.

[2] M. Chen, J.-Q. Hu, and M. C. Fu, "Perturbation analysis of a dynamic priority call center," IEEE Transactions on Automatic Control, vol. 55 2010.

[3] R. J. Benson, T. L. Bugnitz, and W. B. Walton, From Business Strategy to IT Action: Right Decisions for a Better Bottom Line, New Jersey, USA: John Wiley \& Sons, 2004.

[4] James Robertson. (2002). Knowledge Management for Call Centre. [Online]. http:/www.steptwo.com.au/papers/kmc_callcentre/

[5] D. Connor and M. Gutknecht, "Helping clients harness knowledge to drive innovation," PAKM, 1998, pp. 7.

[6] R. Suratida and M. Settapong, "Information technology implementation by applying NIE - SDLC model: the case study on an organization in thailand," in Proc. IEEE International Engineering Management Conference, 2005, pp. 250-254.

[7] K. C. Laudon and J. P. Laudon, Management Information Systems: Managing the Digital Firm, New Jersey, USA: Pearson Prentice Hall, 2004.

[8] E. Turban, E. Mclean, J. Wetherbe, N. Bolloju, and R. Davison, Information Technology for Management: Transforming Business in the Digital Economy, New Jersey, USA: John Wiley \& Sons, 2002.

[9] S. Haag, Management Information Systems for the Information Age, McGraw-Hill Ryerson, Limited, 2001.

[10] W. G. Zikmund, Business Research Methods, Thomson/South-Western, 2003.

[11] J. J. Jiang and G. Klein, "Risks to different aspects of system success," Information and Management, vol. 36, pp. 263-272, April 1999.

[12] E. Y. Li, "Software testing in a system development process: A life cycle perspective," Journal of Systems Management, vol. 41, no. 8, pp. 23-31, 1990 .

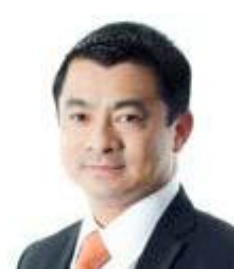

Settapong Malisuwan was born on 24th March 1966 in Bangkok, Thailand. He received his $\mathrm{PhD}$ in electrical engineering (telecommunications), specializing in mobile communication systems from Florida Atlantic University (State University System of Florida), Boca Raton in 2000. He received an MSc in electrical engineering in mobile communications system, from George Washington University in 1996, an MSc in electrical engineering in telecommunication engineering from Georgia Institute of Technology in 1992 and a BSc in electrical engineering from the Chulachomklao Royal Military Academy, Nakhon-Nayok, Thailand in 1990. He served in the Royal Thai Armed Forces for more than 25 years and is currently the Vice Chairman of National Broadcasting and Telecommunications, Bangkok, Thailand. His research interests are in efficient spectrum management and Telecommunications policy and management in Thailand. Col. Dr. Settapong Malisuwan is currently the Elected Vice Chairman and Board Member in the National Broadcasting and Telecommunications Commission, Thailand.

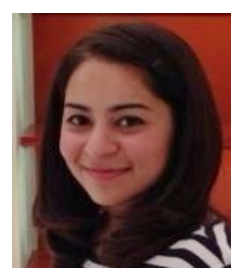

Navneet K. Madan was born in Bangkok, Thailand on 22nd April, 1987. She received her bachelor of business administration in international business management from Mahidol University in 2008, and received Master of Science degree in strategic management and marketing, Middlesex University, London, United Kingdom. She has been working as an Assistant to Vice Chairman in National Broadcasting and Telecommunications, Bangkok, Thailand since January 2012. Her research interests are in Spectrum Management Strategic Flexibility, Market Orientation and Environmental Uncertainty in Fast Clockspeed Industries. 
Wassana Kaewphanuekrungsi was born on 1 st February 1979, Bangkok, Thailand. She received her B.S. in statistics from Chulalongkorn University, Thailand, 2000, and M.S. in Technology Management from Thammasat University, Thailand, 2006. She joined National Broadcasting and Telecommunication Commission (NBTC) as Assistance to Vice Chairman of NBTC in December 2011, which is responsible in the field of telecommunications planning and microstrip antenna design. Previously in 2010, she worked for as senior system analyst at Bangkok Insurance (Public)Co.,Ltd. Her research interests are in information technology, telecommunication technology, wireless communication and antenna design.

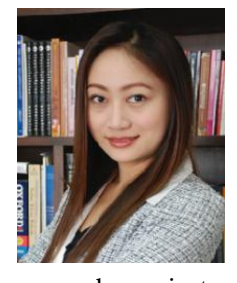

Napaporn Petchinda received her bachelor of business administration from Rangsit University, Thailand, and Master degree of Science and Technology from Assumption University, Thailand. She is currently working as a Chief Executive Officer at Inner-group Company Limited, Thailand. She is currently in the process of achieving her $\mathrm{PhD}$. In Computer And Engineering Management. She worked on several research projects in diverse fields and specializes in managing all communication channels both mass media and internal media. Her current research interest is in Business management, Information System Management and Public Relations. 